\title{
O GRABEN DA FAZENDA RETIRO GRANDE E OUTROS ASPECTOS NEOTECTÔNICOS NA REGIÃO DA PRAIA DE REDONDA (CEARÁ)
}

\author{
Joaquim Raul Torquato (*), Ana Maria Pires Torquato (**) \\ \& Roberto Mendonça de Moraes (***)
}

\begin{abstract}
This paper describes neotectonic characteristics on a shore area named Redonda, Icapuí county, in the northeastern region of the State of Ceará. A moderate dimensioned graben (114m width and a maximun net slip of 50m) was identified, including sediments of the Barreiras and Açu formations. Also, in all area, normal-, vertical-, some positive flower-faults, and conjugate fault systems, besides clastic dykes are spreaded out. A horizontal direction on the $\mathrm{N} 80^{\circ} \mathrm{W}$ direction was identified that correponds to a maximum compressive stress $\left(\sigma_{1}\right)$
\end{abstract}

\section{INTRODUÇÃO}

Assunto quase considerado "tabu" até à alguns anos atras, a neotectônica vem-se firmando cada vez mais como ciência indispensável ao estudo da configuração atual do modelado continental. Por outro lado, também esta nova ciência nos fornece um vínculo que só agora começa a ter forma, e hoje pode ser considerado como indissociável, entre geólogos e geógrafos; os primeiros determinando as condições sedimentares e ambientais dos locais afetados por tectônica recente, os segundos explicando o seu modelado e condições climáticas em que ele ocorreu, $\mathrm{e}$, ambos, trabalhando em conjunto, determinando os parâmetros estruturais que foram dar origem ao acidente neotectônico.

Um dos problemas que normalmente se levanta quando se pretende realizar o estudo neotectônico de determinada região, é o de saber onde terminam os processos geodinâmicos clássicos e começam os relativos à neotectônica. No caso do Ceará adotamos como limite os processos cronológicos pós Bacia Potiguar, afetando diretamente, deste modo, a Formação Camocim, o Grupo Barreiras e as diversas litologias quaternárias quer na região litorânea, quer no interior do Estado. É evidente que, em regiões intraplaca, longe destas unidades estratigráficas, os efeitos da neotectônica ficam impressos em qualquer tipo de rochas, quer sob a forma de altos ou baixos estruturais, quer mostrando fortes mudanças na rede hidrográfica local quer ainda indicando movimentos marcantes em rochas cristalinas.

No Ceará poucos tem sido os trabalhos, de índole neotectônica, levados a cabo, só Saadi \& Torquato (1992 a,b) e Maia et al. (1993) abordaram este tipo de problema.

Com a presente publicação pretende-se apresentar o resultado dos estudos efetuados a oeste-noroeste da Praia de Redonda, entre o sítio Retirinho e a Ponta Grossa (Figura 1).

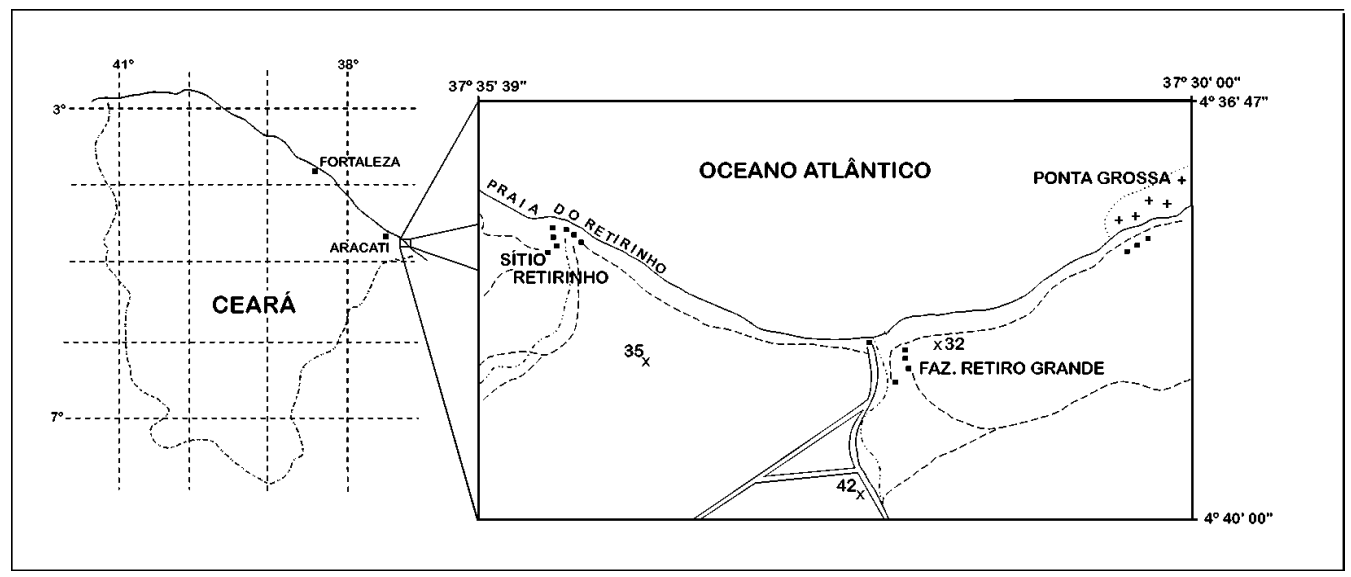

Figura 1: Localização da região estudada. As fotografias correspondentes aos desenhos das figuras 4 a 7 foram tiradas entre a Fazenda Retiro Grande e a Praia do Retirinho.

Figure 1: Map of the studied area. The correspondent photos to the structural scheme on the figures 4 through 7 was taken between Fazenda Retiro Grande and Praia do Retiro. 


\section{O GRABEN DA FAZENDA RETIRO GRANDE}

Situado praticamente a meio caminho entre as praias de Retirinho e Ponta Grossa, encontra-se uma brusca quebra de relevo na falésia de sedimentos Barreiras, a qual podia ser exclusivamente explicada por processos erosivos relacionados à presença pretérita de um paleorio, ou, uma vez que se observa a presença de uma depressão bem alinhada entre a praia e o interior da fazenda, também se admitiu a hipôtese de uma estrutura de afundamento. Para determinar qual a opção correta realizaram-se algumas sondagens elétricas verticais, de modo que a região em causa ficasse abrangida por elas. Foram feitas 5 estações com o objetivo principal de identificar os tipos sedimentares que ocorrem na área, a espessura dos sedimentos e a profundidade do embasamento, para isso utilizou-se o arranjo Schlumberger o qual consiste de quatro elétrodos, sendo 2 para enviar a corrente elétrica e os outros dois para determinar o gradiente de potêncial criado pelo envio e a chegada da corrente. Neste trabalho os equipamentos utilizados foram a fonte REN-10 e os receptores ER-300 ou R-85. O REN-10 foi elaborado pela Fundação Núcleo de Teconologia do Ceará (NUTEC), o ER-300 pela Multitron-RJ e o R-85 pela GEOTEST-PA.

As curvas de resistividade aparente foram suavizadas e depois interpretadas pelo método clássico do ponto auxiliar, utilizando-se as curvas padrões de Orellana-Mooney. Cada curva suavizada foi amostrada em seis intervalos por ciclo e modelada a partir dos parâmetros iniciais obtidos no processo gráfico do ponto auxiliar. Utilizaramse na modelagem e na inversão os filtros lineares contidos em Koefoed (1979) e também um computador IBM-PC para gerar curvas teóricas através de programas elaborados no Laboratório de Geofísica Aplicada do DEGEO/UFC.

No perfil realizado junto à praia, com direção E-W/NW-SE, todas as curvas mostraram um padrão do tipo QKH (Figura 2) onde foi possível identificar perfeitamente, através da variação óhmica, as rochas cristalinas do embasamento, as litologias argilosas
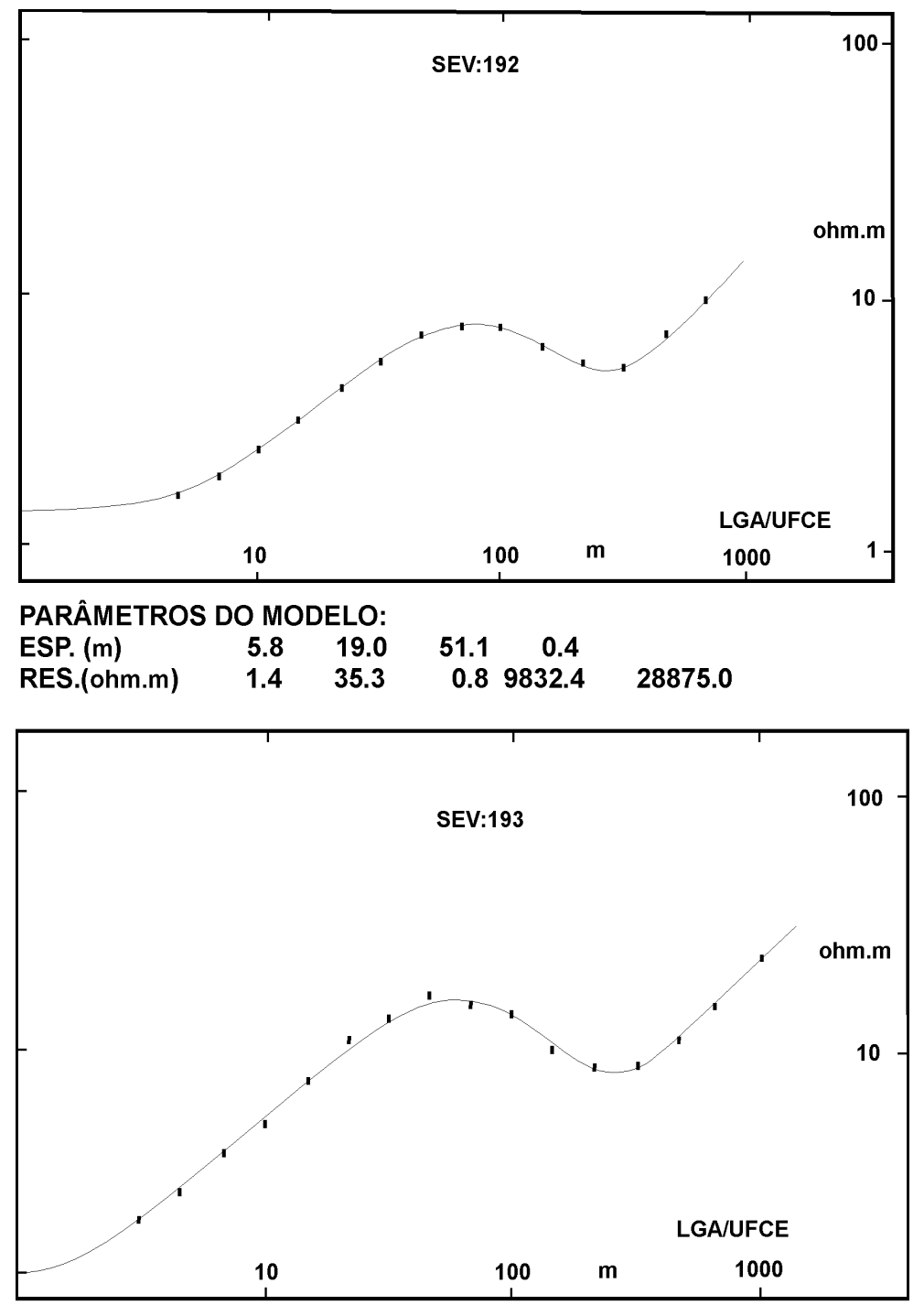

PARÂMETROS DO MODELO:

$\begin{array}{llll}\text { ESP. }(\mathrm{m}) & 2.2 & 2.3 & 30.6\end{array}$

$\begin{array}{lllll}\text { RES.(ohm.m) } & 1.3 & 534.1 & 0.8 & 220.4\end{array}$
Figura 2: Exemplos de duas das SEV's realizadas na região. $\mathrm{Na}$ SEV 192 vê-se perfeitamente a presença dos quatro tipos de litologias: Dunas, Barreiras, Açu e Embasamento não alterado. $\mathrm{Na}$ SEV 193 o Embasamento mostra-se bastante intemperizado.

Figure 2: Vertical Electroresistivity Survey nrs. 192 and 193. In the VES 192, four lithological units are shown: dunes, Barreiras fm., Açu fm. and non-weathered cristalline basement. In the VES 193, a high graded weathering in the cristalline basement is shown. 
da Formação Açu e os sedimentos pouco consolidados e arenosos do Grupo Barreiras, isto além de um pequeno pacote de dunas recentes. As variações óhmicas encontradas foram de 0,8 ohm.m para o pacote do topo (sedimentos recentes embebidos em água salobra) e valores acima de 10 ohm.m para as litologias do Grupo Barreiras, mostrando que o nível de água salobra não atinge este pacote. As rochas da Formação Açu apresentaram resistividades da ordem de 0,8 a 4 ohm.m, perfeitamente identificadas nas curvas pela forte variação em relação aos sedimentos Barreiras, e finalmente o embasamento cristalino com valores superiores a 9.000 ohm.m quando rocha sã, baixando até cerca de 220 ohm.m quando alterada.

Interpretadas as curvas, foi possível elaborar o corte esquemático apresentado na Figura 3 o qual nos mostra perfeitamente a presença de uma estrutura do tipo graben afetando não só a capa superficial de sedimentos Barreiras, mas também todo o conjunto inferior de sedimentos Açu e o próprio embasamento cristalino. O falhamento parece ter sido do tipo "falha em crescimento", uma vez que a espessura das litologias Barreiras, e só elas, aumenta fortemente na região afetada, mostrando que a falha estava ativa durante a deposição dos sedimentos.

\section{OUTRAS ESTRUTURAS DA REGIÃO}

Afetando exclusivamente os sedimentos do Grupo Barreiras, entre a fazenda Retiro Grande e a praia do Retirinho, a cerca de 3 quilômetros da primeira, ainda é possível encontrar um conjunto de estruturas frágeis afetando especialmente uma camada arenosa, esbranquiçada, por vezes conglomerática, posicionada entre dois níveis avermelhados, o inferior, de composição mais grossa, chegando mesmo a conglomerática, o superior, de granulação mais fina.

Falhas normais, falhas verticais, algumas do tipo flor positiva, falhas conjugadas e diques clásticos, podem ser facilmente encontrados em toda a área (Figuras 4 a 7 ).

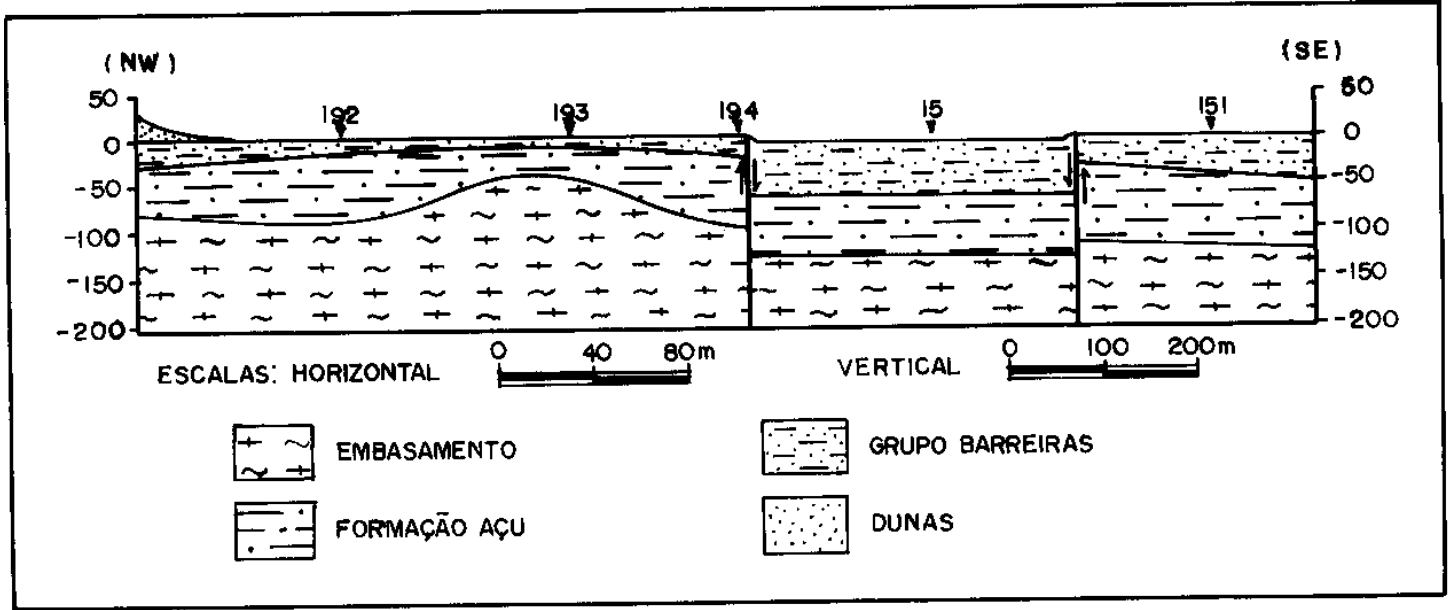

Figura 3: Perfil esquemático do "graben" da Fazenda Retiro Grande. Notar que a espessura dos sedimentos Barreiras é muito maior na região do "graben" do que fora dela.

Figure 3: Schematic profile of Fazenda Retiro Grande graben. Note that the thickness of Barreiras fm. is too much bigger in graben area than outside of it.
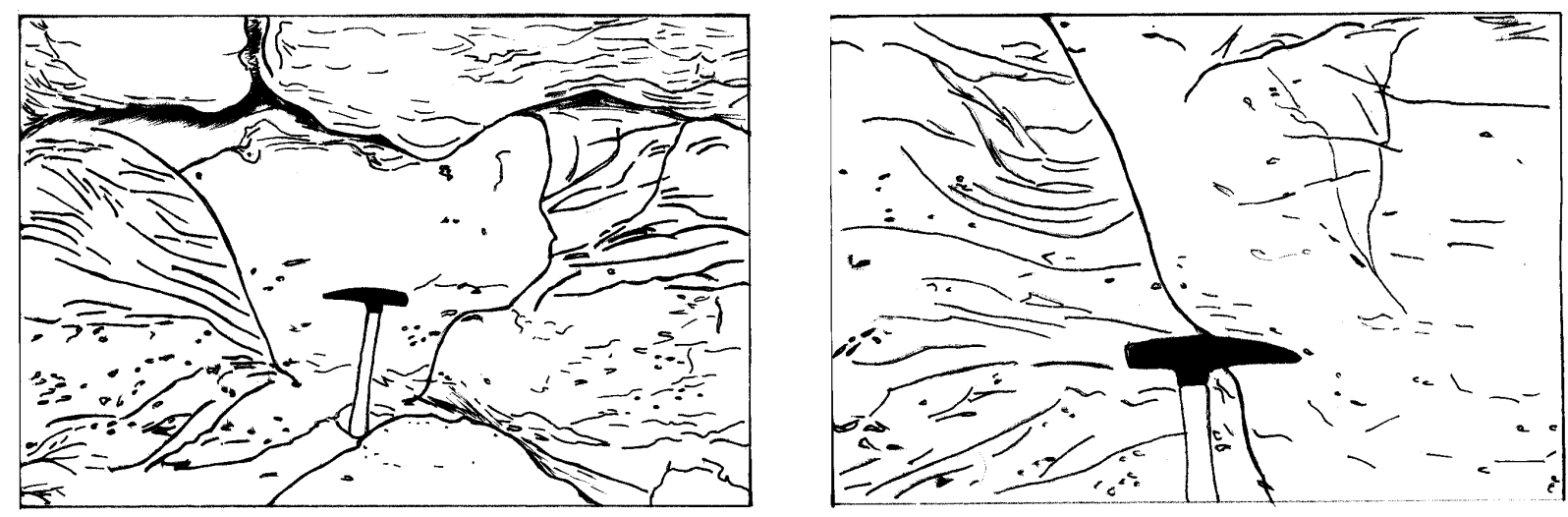

Figura 4: a) Caixa de falha preenchida por arenito do Grupo Barreiras. Notar que o material de preenchimento é menos conglomerático que o encaixante. b) pormenor da região centro-esquerda do desenho anterior, aqui, a linha de falha está perfeitamente visível.

Figure 4: a) Sandstone of the Barreiras Group filling the fault space. It is lesser coarse-grained than the rock walls one. b) Detail of the western area in the figure 3, where the fault line is more visible. 


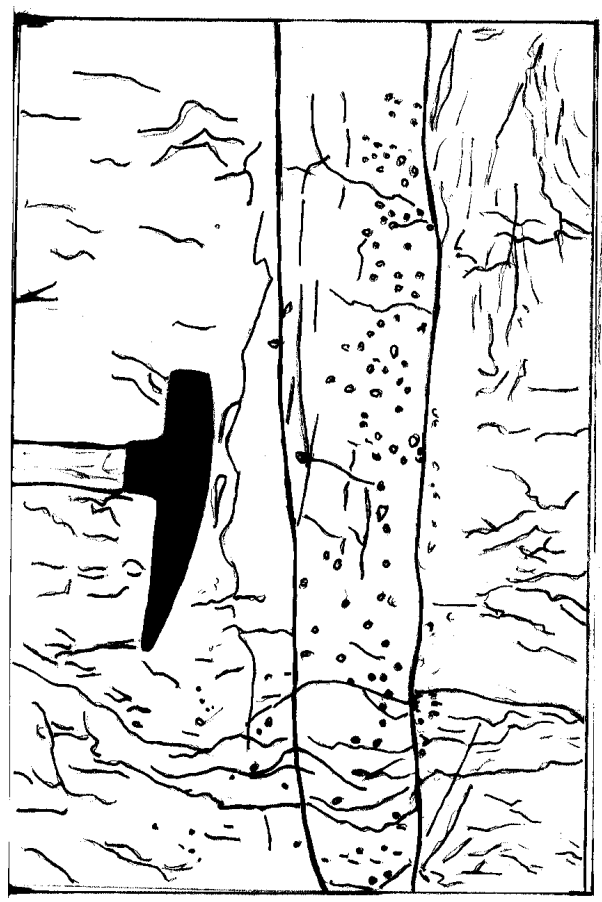

Figura 5: Falha vertical nos sedimentos Barreiras preenchida por material arenítico conglomerático.

Figure 5: Vertical fault in the sediments, filled with conglomeratic sandstone.

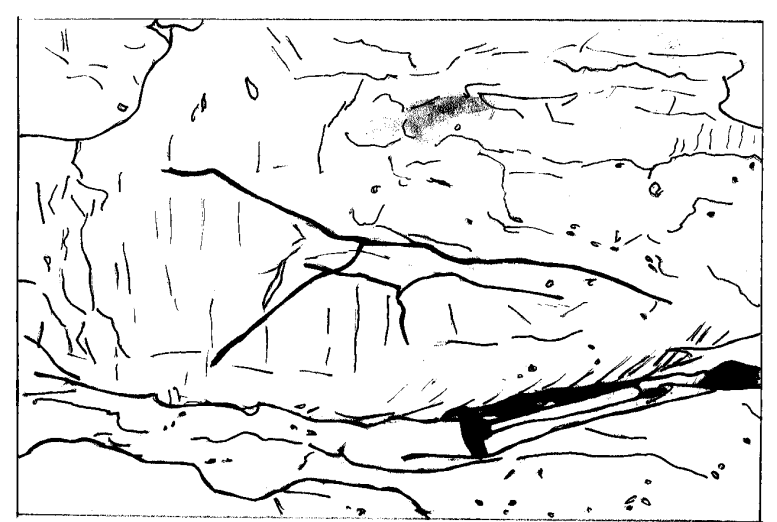

Figura 6: Fraturas conjugadas na parede da falésia dos sedimentos Barreiras. O esforço principal seria quase vertical, segundo a bissetriz do ângulo formado pelas fraturas. Do lado direito do desenho, no local onde se posiciona o bico do martelo, uma fratura vertical corta toda a seqüência.

Figure 6: Conjugate fracture system in the cliff walls of Barreiras sediments. The main stress would be vertical according to the angle they form. At right side, where the hammer is seen, a vertical fracture cut all sedimentary sequence.

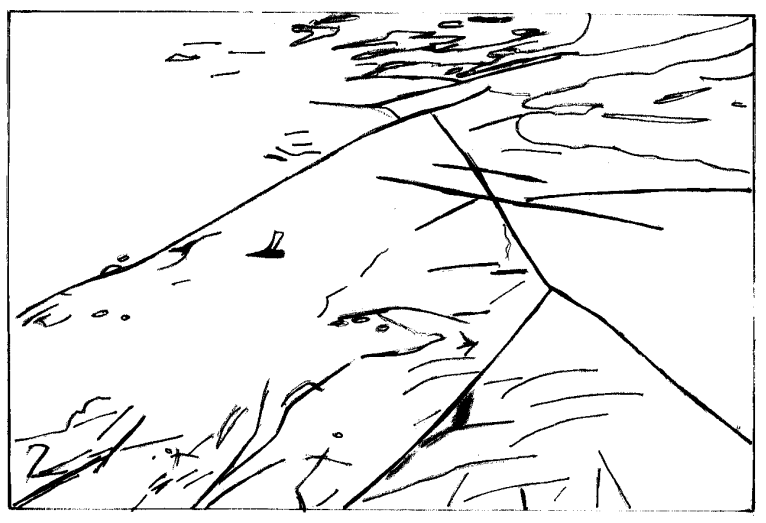

Figura 7: Fraturas conjugadas ao nível da praia mostrando que o esforço principal foi horizontal e praticamente paralelo à linha de costa. Estas fraturas poderão estar relacionadas com as tensões resultantes da deriva continental.

Figure 7: Conjugate fracture system at shore line, showing that the main stress is horizontal and smoothly parallel to the coast line. These fractures could be related to the continental drift stresses.

De evidenciar que, na região da praia do Retirinho, foram observadas falhas conjugadas em dois pontos observados a menos de 200 metros de distância um do outro, o primeiro situado ao nível da praia, o segundo na encosta da falésia, uns 2 ou 3 metros mais alto que o primeiro. No primeiro o esforço principal (sigma 1) é horizontal e de direção $\mathrm{N} 80^{\circ} \mathrm{W}$, quase paralelo à linha de costa, enquanto que, no segundo, torna-se vertical. É possível que este último represente unicamente processos de compactação e só o primeiro, pela sua direção, esteja relacionado com os esforços remanescentes da deriva continental. 


\section{REFERÊNCIAS BIBLIOGRÁFICAS}

MAIA, L.P.; MORAIS, J.O. de ; TORQUATO, J.F. (1993) Aplied geophysics to neotectonics in Aracati-Ceará region, Northeast Brazil. Revista de Geologia. DEGEO/UFC, 6:57-64.
SAADI, A. \& TORQUATO, J.R. (1992) Neotectônica do Ceará: Uma hipótese de interpretação global. In: Cong. Bras. Geol. 37. São Paulo, 1992, Bol. Res. Expandidos... São Paulo, SBG, v.1. p.597-598.

SAADI A. \& TORQUATO, J.R. (1992) Contribuição à neotectônica do Ceará. Revista de Geologia,DEGEO/UFC. 5:5-38. 